\title{
O processo de produção de hipertextos em curso superior: alternativa didática para constituir-se como autor
}

\section{The process of hypertext' production in superior courses: didactic alternative to be a writer}

\author{
Lina Cardoso Nunes*
}

\begin{abstract}
RESUMO
Este artigo apresenta os resultados de uma alternativa didática, desenvolvida no âmbito da ação-investigação, em um curso de Pedagogia. O objetivo foi a produção de um hipertexto. A ação-investigação foi realizada durante três semestres - de 2002/2 até 2003/2, em turmas de sexto período do referido curso. O propósito do estudo foi superar, no decorrer do processo, os entraves na leitura e na escrita, para alcançar a meta da autoria. Foi avaliada como uma experiência bem-sucedida, se considerarmos os resultados obtidos na integração dos processos de ensinar-aprenderavaliar.

Palavras-chave: hipertexto, ensino, aprendizagem, avaliação, ensino superior.
\end{abstract}

\begin{abstract}
This article presents the results of a didactic alternative, developed in the scope of the action-research, in a course of Pedagogia that has the aim of producing a hypertext. The action-research was carried out during three semesters of $2002 / 2$ up to $2003 / 2$, in groups of the sixth period of the

* Doutora em Educação (UFRJ). Professora da Universidade Estácio de Sá - Rio de Janeiro. E-mail: linanunes@ig.com.br
\end{abstract}


related course. The aim of the study was to surpass, in elapsing of the process, the difficulties of reading and writing, to reach the goal of the authorship. It was evaluated as a well-succeeded experience, if we consider the results gotten in the integration of the processes of teaching-learningevaluating.

Key-words: hypertext, teaching, learning, evaluation, university education.

\section{Apresentando a proposta}

Este artigo pretende enfocar uma alternativa didática proposta em um curso de Pedagogia, com o propósito de articular os procedimentos de ensinar, aprender e avaliar, no percurso das atividades desenvolvidas intra ou extra-muros da sala de aula. Tendo em vista a temática da disciplina - as relações entre a Educação e as tecnologias da informação e comunicação - a meta da alternativa proposta voltou-se para as possibilidades de produzir um hipertexto, que reunisse as palavras-chave e as idéias principais dos textos trazidos por alunos e professor, integradas à consulta dos materiais coletados nos diferentes meios de informação e comunicação, no decorrer da disciplina.

Essa idéia nasceu de uma necessidade de rever o processo de ensino, com a perspectiva de apresentar uma alternativa que fosse além das estratégias comumente aplicadas no ensino superior, tentando, especialmente, a superação das dificuldades de constituir-se como autor e vencer os desafios da leitura e da escrita, apresentados na era digital, quando novas modalidades de ler e escrever estão disponíveis para alguns privilegiados. "A textualidade eletrônica esboça um novo idioma formal facilmente decifrável por todos". (CHARTIER, 2002, p. 17): é o caso da invenção de símbolos, maneira pictográfica para indicar o registro de significados das palavras, que busca uma linguagem não-verbal, que permite a expressão de emoções e sentidos do discurso. Assim emergiu a presente proposta, lançando mão dessas novas formas de expressão, aliadas às tradicionais já utilizadas nas salas de aula presenciais, que evocam as práticas de leitura e escrita.

Soares (2002, p. 145) mostra a importância da compreensão do letramento, na busca de um novo sentido, não mais da cultura do papel, mas no contexto da cibercultura. A autora chama a atenção para a concepção de letramento como sendo 
não as práticas de leitura e escrita, e/ou os eventos relacionados ao uso destas práticas, ou ainda o impacto ou conseqüências da leitura sobre a sociedade, mas para além da leitura e da escrita é parte integrante da interação entre pessoas e do processo de interpretação dessa interação.

A autora em foco afirma que no quadro desse conceito de letramento "o momento atual oferece uma oportunidade extremamente favorável para refinálo e torná-lo mais claro e preciso" (SOARES, 2002, p. 146), tendo em vista as recentes formas de tecnologias de comunicação eletrônica - o computador, a rede (web) e a Internet. Aqui se insere a idéia de hipertexto, possibilitado pela escrita na tela do computador.

Recorremos inicialmente a Levy (1993, p. 73), com o objetivo de esclarecer o significado de um hipertexto. $\mathrm{O}$ autor explica que

a metáfora do hipertexto dá conta da estrutura indefinidamente recursiva do sentido, pois já que ele conecta palavras e frases cujos significados remetem uns aos outros, dialogam e ecoam mutuamente para além da linearidade do discurso, um texto já é um hipertexto, uma rede de associações.

Nesse sentido, foi encaminhada a idéia da alternativa didática proposta para o curso, ministrado no ensino superior, no curso de Pedagogia, nos anos 2002 e 2003, que consistia em construir textos, ou melhor, hipertextos, em que progressivamente fosse criada uma rede de associações, cujos significados dialogassem entre si, na busca de relações entre educação e tecnologias da informação e comunicação.

Apoiados nas idéias de Levy (1993, p. 33) orientamos os alunos explicitando que

um hipertexto é um conjunto de nós ligados por conexões. Os nós podem ser palavras, páginas, imagens, gráficos ou partes de gráficos, seqüências sonoras, documentos complexos que podem ser eles mesmos hipertextos. Os itens de informação não são ligados linearmente, como uma corda com nós, mas cada um deles, ou a maioria, estende suas conexões em estrela, de modo reticular. 
Funcionalmente, Levy (1993, p. 33) considera que “ um hipertexto é um tipo de programa para a organização de conhecimentos ou dados, a aquisição de informações e a comunicação". Nesse contexto, encontramos a idéia que buscávamos. Não simplesmente ser o docente de uma disciplina, mas criar um espaço no qual os aprendizes organizassem o conhecimento no âmbito de uma nova cultura de aprendizagem (POzo, 2002),

Para Ramal (2002), outro referencial que orientou nossa proposta, o hipertexto possibilita e pode até exigir a colaboração de muitos autores para sua produção, o que implica na redefinição de papéis de leitor e autor, favorecendo uma visão bem diferente dos modelos tradicionais de leitura e escrita. A autora em foco alerta que o hipertexto facilita o desenvolvimento de trabalhos de forma coletiva e o estabelecimento de comunicações e apropriação de informações num enfoque cooperativo.

Ramal (2002, p. 67) esclarece que algumas pessoas identificam o hipertexto somente "em textos eletrônicos, produzido em determinado tipo de meio ou de tecnologia, no entanto ele não deve ser limitado a isso, já que consiste numa forma organizacional que tanto pode ser concebido para o papel, como para o ambiente virtual".

Cada página da rede digital é construída por vários autores. "Cada percurso textual é tecido de maneira original e única pelo leitor cibernético" (RAMAL, 2002, p. 84). O leitor é um sujeito coletivo, que navega com outros leitores, interagindo com eles e produzindo novos conhecimentos, no espaço cibernético.

Vale registrar, no que tange à apropriação de conhecimentos, que "a humanidade desenvolveu quatro ideais ou tipos de relação com o saber" (PELlANDA, N. M. C.; PELLANDA, E. C., 2000, p. 17): nos primeiros tempos, antes da escrita o saber era ritual, isto é, encarnado por uma comunidade viva, representada pelos velhos que transmitiam os conhecimentos de geração para geração; o segundo tipo de relação com o saber foi o trazido pelos livros; como exemplo, Pellanda e Pellanda (2000) citam a Bíblia, por meio da qual a figura do conhecimento é o intérprete; com a chegada da imprensa, a biblioteca toma o lugar dos livros; nesse caso, volumes e volumes reuniam-se nas enciclopédias, sendo que cada tema remetia a outro tema - uma espécie de hipertexto, muito diferente do livro, passando à figura do erudito, do sábio; hoje "assistimos à desterritorialização das bibliotecas" (PELlandA, N. M. C.; PELlANDA, E. c, 2000, p. 18). Segundo os autores, voltamos às origens, quando o portador do conhecimento era a humanidade viva.

É o que os autores denominam de espaço cibernético. Um hipertexto, atualmente, "não acompanha a velocidade com que circula a informação" 
(Pellanda, N. M. C.; Pellanda, E. C, 2000, p. 18). A mídia opera em fluxos e ninguém consegue deter as informações que se avolumam dia a dia, somos atropelados pelas notícias em jornais, revistas, televisão, Internet, numa explosão de novidades que freqüentemente não conseguimos digerir.

Nas salas de aula, diante do professor, os participantes podem assumir uma postura estática, no entanto, borbulham pensamentos, idéias, opiniões, que nem sempre se expressam oralmente. É um espaço acadêmico, com carteiras dispostas horizontalmente, nem sempre favoráveis à troca de idéias e expressão da oralidade. Tínhamos como objetivo reformular esse espaço, tentando reverter a postura dos alunos, de maneira que pudessem expressar-se livre e criativamente, a fim de que mais facilmente alçassem vôo e pudessem produzir seus próprios textos.

Entendíamos assim que em um curso de Pedagogia, precisávamos criar um ambiente facilitador para a oralidade que despertasse o desejo de escrever, com a perspectiva de viabilizar um processo, que fosse além de transmitir informações e organizar conteúdos em torno da temática da disciplina, mas favorecesse uma produção individual e coletiva, criando alternativas para a construção do conhecimento. Acreditávamos que a expressão oral e escrita pode emergir em um ambiente dialógico entre mestres e aprendizes.

Foi com este propósito que sugerimos aos alunos a produção de hipertextos, no percurso da disciplina, objetivando relacionar os textos propostos para análise com os materiais coletados em jornais, revistas, que poderiam ser gravuras ou fotografias, textos de outras disciplinas e/ou textos capturados na Internet, relacionados com as questões emergentes vinculadas à temática: as relações entre Educação e tecnologias da informação e comunicação, no curso de Pedagogia. As estratégias utilizadas com esse objetivo, em nosso entender, favoreceriam as perspectivas de tecer as relações entre os processos de ensinar, aprender e avaliar.

Sob tal ótica, desejávamos assegurar especialmente aos estudantes que criassem seus próprios textos e materiais de estudo, "com base na leitura, análise e interpretação dos meios, canais e suportes de comunicação, na condição de protagonistas, ativos, e não apenas como consumidores de textos e produtores de materiais produzidos por terceiros" (FIORENTINI, 2003, p. 16)

Buscávamos assim ir além do papel do professor que somente propõe "receitas, guias e diretrizes, normas e formas como moldura para sua ação" (FIORENTINI, 2003, p. 17), mas encaminhar o aprendiz para ser autor, numa nova perspectiva de aprender (POZO, 2002). Nessa linha de raciocínio, Fiorentini (2003, p. 25) faz referência a Piaget (1978) para apoiar a reflexão sobre os professores que planejam cursos e se envolvem com a elaboração de textos 
para a aprendizagem e a Vygotsky (1989, p. 78), que explica a atividade da mente - a consciência de estar consciente - o conhecimento metacognitivo. Vygotsky (1989) explica os conceitos de metaconsciência, que podem ser estendidos à concepção de textos, de cursos e materiais de ensino e de aprendizagem, porque

possibilitam deliberada e consciente utilização de estratégias e procedimentos necessários à resolução de problemas do conhecimento em questão - pela detecção, observação, reparação de dificuldades de compreensão, pelo gerenciamento de recursos cognitivos, pelas atividades de revisão e reestruturação

Fiorentini (2003) alerta sobre os desafios que emergem no processo de autoria de textos escritos, dos quais destacamos a que se refere à garantia da atividade do aprendiz e da qualidade de sua participação. Nessa oportunidade, cabe lembrar que reiteradas vezes os aprendizes demonstram-se interessados na atividade de escrever, no entanto sua participação é incipiente, passageira.

Assim, observávamos na prática da sala de aula que ao colocar nas mãos dos alunos uma folha em branco, solicitando que escrevessem sobre um tema, mesmo que livre, parecia constituir-se num desafio registrar a primeira palavra, elaborar a frase inicial... Não falta o desejo de escrever, mas um certo medo de cobrir a primeira página... A produção textual na tela do computador também apresenta os mesmos entraves, sendo mais fácil ler e copiar, transcrever as idéias, ou reunir vários textos sobre um tema, do que produzir um texto, constituindo-se como autor.

Soares (2002, p. 150) alerta que "no computador, o espaço da escrita é a tela ou "a janela"; ao contrário do que ocorre quando o espaço da escrita são as páginas do códice, quem escreve ou quem lê a escrita eletrônica tem acesso, em cada momento, apenas ao que é exposto no espaço da tela". Mais adiante Soares (2002, p. 150 ) chama a atenção para que "a escrita na tela possibilita a criação de um texto diferente do texto no papel”. O que estava em jogo para nós, como professores, era justamente o impulso para a criação, tendo em vista que cada aprendiz se constituísse como autor, na folha em branco ou na tela do computador.

A autoria representa o compromisso com o conhecimento, com o sentido do que aprendemos. A proposta de passo a passo desvelar, compreender o que está escrito por muitos autores e atribuir um sentido pessoal ao que escre- 
vemos sobre o que compreendemos daquilo que lemos, se configura como a autoria. Aqui vale lembrar as relações emergentes entre o pensar, o falar e o escrever. Daí a preocupação do professor em estimular a reflexão, oportunizando a expressão das idéias e sua transcrição textual.

Koch (2001, p. 62) mostra "a visão dicotômica entre a fala e a escrita" e suas diferenças; a primeira, entre outras características, é contextualizada, implícita, não-planejada, fragmentada, pouco elaborada, enquanto a segunda se apresenta descontextualizada, explícita, planejada, não-fragmentada, elaborada. Assim, parece mais fácil falar que escrever.

Todavia Koch (2001) explica que nem todas as categorias são exclusivas de uma ou de outra modalidade e que essas características tomaram por modelo a escrita, o que levou a uma visão preconceituosa da fala. Na verdade, de acordo com o autor, a fala tem características próprias, entre as quais podemos citar: é relativamente não-planejável, pois no texto falado ocorre simultaneamente o planejamento e a verbalização, já o fluxo do texto falado é descontínuo, enquanto o da escrita é resultado de um processo, numa dimensão estática, enquanto a fala é também processo, mas de caráter dinâmico.

As formulações teóricas dos referidos autores (CHARTIER, 2002; LEVY, 1993; SOARES, 2002; POZO, 2002; RAMAL, 2002; PELLANDA, N. M. C. e PELLANDA, E. C., 2000; FIORENTINI, 2003; косH, 2001) foram fundamentais para orientar o processo que será a seguir relatado.

\section{Descrevendo o processo de ação-investigação}

Torna-se oportuno clarificar que as atividades aqui registradas não se configuraram somente como ação pedagógica, mas ambicionávamos avançar no caminho da investigação de novas formas de ensinar, aprender e avaliar, num processo de ação-investigação. Enquanto ensinávamos, refletíamos e pesquisávamos sobre os referenciais da disciplina Educação e Tecnologias da Informação e Comunicação, que na verdade, constituíam-se em referências teóricas para o próprio processo de pesquisa que vivíamos em nosso ofício de professor-pesquisador, com e sobre os aprendizes e sobre nossa própria atuação. Durante os três semestres em que empreendemos essa ação-investigação, tínhamos a ementa da disciplina e os objetivos, que foram assim definidos: refletir sobre o processo de alfabetização; analisar o impacto das 
tecnologias nas práticas educativas, numa perspectiva histórica; discutir as possibilidades da inserção das novas tecnologias de comunicação e informação na Educação; identificar novas linguagens advindas das inovações tecnológicas e subsidiar a atuação pedagógica numa perspectiva que considere não só a incorporação de novas tecnologias mas, sobretudo, sua apropriação crítica.

Ao iniciarmos o semestre apresentávamos a proposta, buscando criar um ambiente propício para a inovação que pretendíamos aplicar, indicando os procedimentos que seriam utilizados e as modalidades de avaliação a serem desenvolvidas. Inicialmente havia certa desconfiança e resistência dos alunos na forma pela qual orientávamos a disciplina, que iam progressivamente se dissipando no percurso das atividades.

A bibliografia básica, que orientava o estudo do mestre e dos aprendizes constava dos seguintes autores: Frago (1993) para orientar a discussão sobre os paradoxos da alfabetização; Levy (1993) que enfocava as relações entre escrita, oralidade e Informática; Sampaio e Leite (2001) importante no sentido de analisar a necessidade da alfabetização tecnológica do professor; Pretto (1996) auxiliava no estudo da evolução das inovações tecnológicas e Moran (2001) na reflexão sobre a mediação pedagógica e as aplicações das tecnologias à educação. Cabe registrar, no entanto, que para o mestre eram necessárias outras leituras, indispensáveis no aprofundamento das questões emergentes no processo de pesquisar, ensinar, aprender e avaliar sobre as relações entre a Educação e as tecnologias da informação e comunicação, registradas na primeira parte deste artigo.

Um aspecto importante para a alternativa da proposta em foco - a construção de hipertextos - era a oportunidade de interação, criada na sala de aula, de diálogo sobre os textos apresentados pelo mestre, a partir de estratégias sugeridas preliminarmente para discutir esses textos, que viabilizassem a expressão de opiniões oralmente, ao mesmo tempo em que eram apresentados e analisados os materiais obtidos pelo grupo, coletados em diversos meios de comunicação. Sugeríamos, inclusive, a utilização do correio eletrônico, quando acessível aos participantes. Solicitávamos o e-mail dos alunos e tentávamos a participação daqueles que possuíam Internet, que chegava a cerca de $70 \% \mathrm{em}$ cada turma; no entanto desses $70 \%$, apenas $20 \%$ utilizava o correio eletrônico. $\mathrm{O}$ computador era usado, com maior freqüência para digitação de trabalhos, e menos para outras atividades, como, por exemplo, a consulta à Internet e a correspondência via e-mail ou a participação em fóruns de discussão.

As atividades propostas eram diferentes em cada encontro; a professora variava aplicando, às vezes, estratégias individuais, outras coletivas: estudos 
dirigidos e discussões grupais eram as mais utilizadas. Para alguns temas, em que era considerado necessário, preparava-se uma exposição, apoiada por um recurso visual ou áudio-visual, com abertura para o diálogo e participação dos alunos.

Um aspecto significativo no percurso da disciplina era vinculado à avaliação. Tínhamos a preocupação de integrar à proposta de ensinar-aprenderpesquisar ao processo de avaliar. Nesse contexto, no início do semestre, lançávamos a idéia da elaboração de um portfólio, que seria composto de breve histórico sobre a trajetória de aprendizagem do aluno, notas de aula, coleção de recordações, representações visuais, trabalhos pontuais do período, relativas ao acompanhamento da aprendizagem, conexões com temas fora da aula, notas pessoais sobre o progresso na disciplina, além de artigos e recortes de jornais, revistas, fotografias, músicas, poesias, artigos de livros ou capturados na Internet.

O material reunido seria apresentado em dois momentos - no meio e ao final do período - o que iria representar o caminho percorrido pelos alunos, sua participação e todas as produções elaboradas no decorrer do curso, desenvolvidas na sala de aula e também fora da sala. Explicávamos que o portfólio era uma modalidade de avaliação devedora do campo da arte com possibilidades de aplicação na Educação.

Assim, as atividades dos alunos eram registradas passo a passo e cada um reunia o material sugerido pelo professor nos encontros, além de agregar outros materiais relacionados aos textos indicados pelo professor. Os estudantes poderiam decidir os momentos mais importantes do processo para elaborar o seu portfólio, definindo sua apresentação em pasta, envelope ou álbum (RANGEL; NUNES; GARFINKEL, 2004). Essa modalidade de avaliação era mais uma oportunidade de refletir sobre a aprendizagem da classe em relação aos conteúdos do ensino, e ao mesmo tempo favoreceria a introdução de mudanças no planejamento do professor. É indispensável registrar que os portfólios eram apoios significativos para a construção progressiva dos hipertextos.

A busca contínua de relações entre os textos sugeridos pelo professor era estimulada no decorrer das leituras, que objetivavam encontrar, de início, as palavras-chave de cada texto indicado no decorrer do curso. As palavraschave norteavam nossa atividade de pesquisa das relações entre os textos. Eram como se fossem links, em que "clicando com o mouse" poderiam revelar as relações com os outros textos. Simultaneamente a essa etapa inicial, era solicitado que encontrassem as idéias principais dos textos. Podemos afirmar que havia dificuldades para essas tarefas, visto que nem sempre os participantes conseguiam ler os textos e quando liam custavam, de início, a encon- 
trar as palavras-chave e as idéias principais nos capítulos indicados para leitura.

Ao lançar um texto novo pedíamos para que procurassem as relações entre o texto anterior, o novo texto e outros que tivessem lido e pudessem enriquecer a produção do hipertexto, que representava ir além dos textos, navegando em busca da rede de idéias emergentes das leituras.

Uma das propostas em grupo sobre os textos trabalhados durante o curso foi o "Painel para integração dos textos" por meio da identificação de: conceitos, idéias principais, objetivos do curso, para o encontro de links relações possíveis - entre os conteúdos dos textos estudados e os conteúdos apresentados no curso de "Educação e Tecnologias da Informação e Comunicação".

Para que compreendessem o que desejávamos que fosse produzido, mostrávamos a figura a seguir (Figura 1), sugerindo que revissem as tarefas anteriores e tendo em vista as relações encontradas entre as palavras-chave e as idéias principais dos materiais que davam apoio à disciplina, elaborassem coletivamente um texto. Essa atividade tinha por objetivo prepará-los para a elaboração individual do hipertexto que constituía a meta da disciplina. A interação propiciada pela discussão dos participantes com a consulta dos textos já produzidos anteriormente poderia ser válida para orientar a atividade cognitiva, já indicada anteriormente, orientada para "a consciência de estar consciente" Vygotsky (1989).

\section{Alguns resultados da ação-investigação}

Seria impossível registrar todos os achados resultantes do trabalho desenvolvido durante os três semestres, em que lecionamos a disciplina em foco. Entretanto, como nosso objetivo era a produção de um hipertexto ao final do semestre, selecionamos os textos produzidos por quatro alunos que consideramos resultados expressivos do que é possível alcançar com essa alternativa didática. Nessa oportunidade, a proposta foi que produzissem um hipertexto que reunisse as palavras-chave e idéias principais que nortearam a trajetória na disciplina, integrando o que haviam aprendido naquele período.

Para nós, as produções apresentadas evidenciaram as possibilidades de que o aluno se revelasse como autor de uma produção hipertextual elaborada 


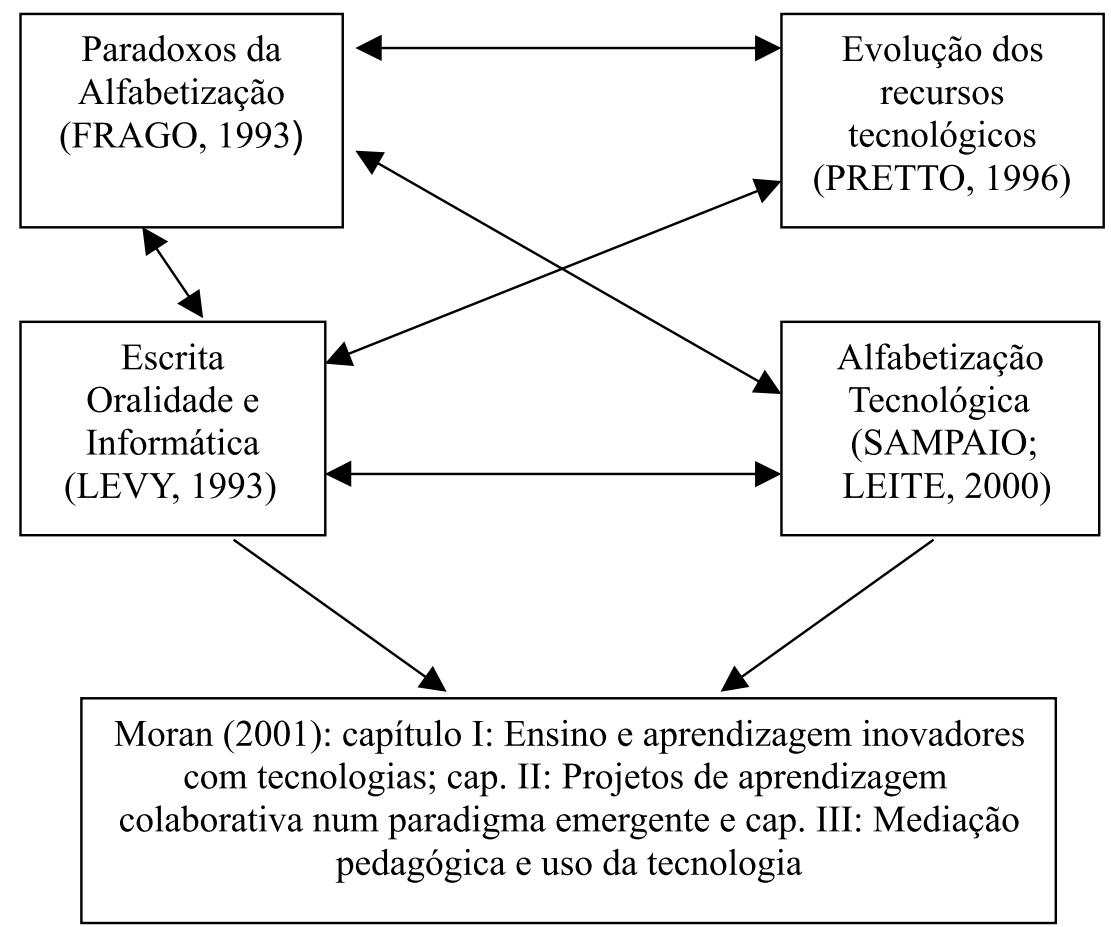

na última fase do percurso da disciplina, a partir da consulta realizada aos materiais por eles reunidos. Após a leitura atenta dos textos selecionados, pudemos destacar temas convergentes que apontam para o alcance dos objetivos propostos pela professora em sua ação-investigação.

Inicialmente, destacamos a importância da leitura e escrita nas produções transcritas, como podemos encontrar nos trechos a seguir:

A escrita explicita a sua importância em cada tempo e em cada local. $\mathrm{Na}$ sociedade atual, basicamente letrada, não conseguir interagir com a escrita significa não interagir com a própria sociedade. (I.R.F.C., 3/12/2003). Até porque só lemos de fato quando conseguimos conversar com o texto, ou seja, interpretá-lo, refletir e tirar conclusões sobre o mesmo. (A.C.F.L., 28/05/2003). 
A questão do letramento é e sempre será uma questão chave no ensino, inserindo os alunos na língua falada e escrita. (P.Z.S, 26/11/2003)

Para que a alfabetização ocorra com naturalidade o leitor deve interagir com os textos, formando sua própria concepção do mundo. (P.Z.S, 26/ $11 / 2003)$

Nesses trechos vemos trabalhadas as idéias discutidas nos textos de Frago (1993) sobre os paradoxos da alfabetização e de Levy (1993), que sinalizam para as relações entre a oralidade e a escrita. Para a constituição da autoria, esses aspectos são essenciais: dialogar com o texto, ser capaz de, por meio da leitura, interpretar e tirar conclusões, buscar e selecionar informações, interagir com a sociedade pela apropriação das informações. No nosso entender, os textos transcritos revelavam a compreensão desses aprendizes-autores sobre a relevância do processo de letramento (SOARES, 2002).

O próximo tema convergente que encontramos nos escritos dos alunos foi possibilidades de comunicação trazidas pelos processos de apropriação das novas linguagens, transcritas nos trechos seguintes:

Num primeiro momento, destaca-se a questão da tecnologização da palavra que atualmente é ampliada pelo computador. Este "aliado" da revolução tecnológica abre espaços para as mais diversas formas de comunicação. (A.C.F.L., 28/05/2003)

A educação, nesta perspectiva, é concebida como um sistema aberto. Os alunos constroem o conhecimento por meio da exploração, da navegação, comunicação, troca, criação e recriação. (G.M.V.C, 5/11/2003)

O educador hoje já não é mais um mero transmissor de conhecimentos. A troca com o grupo é extrema importância, senão fundamental. (P.Z.S, 26/11/2003).

O processo de comunicação no percurso da aprendizagem foi destacado pelos alunos, que compreendem o valor da troca com o grupo e a contribuição do computador como "aliado", abrindo espaços para o diálogo, voltado para uma concepção aberta da educação. Observamos nesses trechos as idéias de Pretto (1996) relacionadas aos processos comunicacionais viabilizados pelas tecnologias da informação e comunicação, através dos tempos, e as possibilidades de mediação pedagógica evocadas por Moran (2001). 
Nessa mesma linha de pensamento emerge o tema sobre aprendizagem colaborativa, lembrada nos seguintes trechos:

Para que tudo isso ocorra o professor precisa reconstruir a sua prática. Optar por metodologias que usem a aprendizagem colaborativa, crítica e transformadora. Precisar romper com a grade de informação do conteúdo. Nesta visão de aprendizagem colaborativa, temos a favor do professor o trabalho com projetos. (G.M.V.C., 5/11/2003)

$\mathrm{Na}$ alfabetização digital os indivíduos também precisam ter um contato com os recursos tecnológicos e a presença de um professor mediador deste conhecimento que facilita a aprendizagem. (P.Z.S., 26/11/2003)

No processo de aprendizagem colaborativa aparece o professor mediador, que é capaz de interagir com os alunos, na reconstrução de sua prática, rompendo com modelos tradicionais de ensino. Embora possamos considerar que as idéias transcritas textualmente nem sempre sejam incorporadas à prática, é na discussão, na troca, na colaboração que pode nascer a vontade de transformar-se e transformar. Na leitura desses trechos recordamos especialmente as discussões sobre o professor-mediador enfocada por Moran (2001) e a urgência da alfabetização tecnológica do professor (SAMPAIO; LEITE, 2000), como personagem na mediação pedagógica, por meio das inovações tecnológicas.

Poderíamos ainda retirar muitos temas que aqui e em outras produções foram emergentes no decorrer dos encontros com esses futuros educadores. No entanto, vamos colocar em relevo o que se relaciona mais estreitamente com a dimensão crítica da disciplina que é o tema da exclusão social e digital, representada pelo analfabetismo funcional e digital, de alunos e professores, pontuado nos seguintes trechos:

Infelizmente grande parte da população brasileira é analfabeta, não estando apta a interatuar com o meio. (I.R.F.C., 3/12/2003).

Toda essa evolução gera possibilidades e espelha os limites que as transformações técnicas e tecnológicas nos trazem. Ao mesmo tempo em que uns fazem um curso a distância, outros continuam marginalizados, sem, no mínimo, saber assinar o próprio nome. (A.C.F.L., 28/05/2003). $\mathrm{O}$ conceito de educar, ensinar e aprender mudou muito ao longo dos anos. Hoje o professor precisa buscar a educação continuada, não pode 
deixar de ler, estudar, ler, participar das evoluções tecnológicas da nossa sociedade. Ele pode não entrar na sala de aula sendo um analfabeto tecnológico, pois os alunos estão chegando na escola com muitas informações, ligadas no mundo virtual, na internet, no mundo tecnológico. (G.M.V.C, 5/11/2003).

A alfabetização não é facilmente encontrada na literatura acadêmica. A utilização dessas tecnologias requer conhecimentos por parte do educador. A sociedade da informação requer a necessidade do domínio dos recursos digitais, pois com a globalização tudo gira em torno da informatização, tudo é informação. (P.Z.S., 26/11/2003).

Os trechos selecionados nesse tema alertam para a importância de todos estarem envolvidos no processo de alfabetização digital, tanto alunos quanto professores, o que remete aos autores estudados Viñao Frago (1993) e Sampaio e Leite (2000). Esse é um dos aspectos críticos que pode ser apontado na sociedade da Informação. O progresso científico-tecnológico mostra o extraordinário desenvolvimento das inovações tecnológicas, caminhando lado a lado com as indiscutíveis diferenças entre as possibilidades de acesso ao mundo digital.

\section{À guisa de conclusão}

A alternativa pedagógica apresentada, no nosso entender, constituiu uma experiência bem sucedida, visto que alunos e alunas, avaliaram a disciplina como oportunidade significativa para seu processo de produção textual, tanto no seu desenvolvimento pessoal, percebendo-se como autores/as de textos, mas especialmente, consideraram-se mais preparados/as para a elaboração de seus trabalhos monográficos de conclusão de curso. A avaliação das produções dos aprendizes e os portfólios apresentados ao final da disciplina sinalizaram para o alcance dos objetivos da disciplina, na riqueza dos materiais coletados pelos participantes - artigos de jornais e revistas, fotos, imagens, textos reunidos - naquela experiência que para nós integrava um processo de ensino-aprendizagem-pesquisa à avaliação pessoal e coletiva. As trajetórias de aprendizagem dos alunos nos emocionaram...

Cabe registrar o trecho a seguir, significativo para o trabalho desenvolvido pelos professores e alunos: a "formação do aluno deve contemplar o 
diálogo, a busca incessante do novo, o desejo de pesquisar, de tornar-se autônomo. $\mathrm{O}$ aluno é visto como um ser global, ele aprende a conhecer, a fazer, a ser, a partilhar. Ele aprende a aprender a aprender. Para que tudo isso ocorra o professor precisa reconstruir a sua prática." (G.M.V.C., 5/11/2003).

A professora aprendeu com os alunos no percurso de seu ofício de mestre, como se tornar autor com o apoio dos recursos tecnológicos de informação e comunicação, criando hipertextos inéditos, alguns bem simples e outros mais consistentes, criativos e crítico-reflexivos, além de refletir criticamente sobre as possibilidades de sua prática mediadora no processo de aprender a aprender a ensinar.

\section{REFERÊNCIAS}

CHARTIER, R. Os desafios da escrita. São Paulo: Unesp, 2002.

. Ordem dos livros: leitores, autores e bibliotecas na Europa entre os séculos XIV e XVII. Brasília: UnB, 1999.

FIORENTINI, L. M. R.; MORAES, R. A. (Orgs.). Linguagem e interatividade na educação a distância. Rio de Janeiro: DP\&A, 2003.

GUTTIERREZ, F.; PRIETO, D. A mediação pedagógica; a EaD alternativa. Campinas: Papirus, 1994.

KOCH, I. V. O texto e a construção dos sentidos. São Paulo: Contexto, 2001.

LEVY, P. As tecnologias da inteligência; o futuro do pensamento na era da informática. Rio de Janeiro: Editora 34, 1993.

MORAES, M. C. O paradigma educacional emergente. Campinas: Papirus, 2000.

MORAN, J. M.; MASETTO, M. T.; BEHRENS, M. A. Novas tecnologias e mediação pedagógica. 2. ed. Campinas: Papirus, 2001.

PELLANDA, N. M. C.; PELLANDA, E. C. (Org.). Ciberespaço: um hipertexto com Pierre Lévy. Porto Alegre: Artes e Ofícios, 2000.

POZO, J. I. Aprendizes e mestres: a nova cultura da aprendizagem. Porto Alegre: Artmed, 2002.

PRETTO, N. L. Uma escola sem/com futuro: educação e multimídia. São Paulo: Papirus, 1996. 
RAMAL, A. C. Educação e cibercultura: hipertextualidade, leitura, escrita e aprendizagem. Porto Alegre: Artmed, 2002.

RANGEL, J.; NUNES, L. C.; GARFINKEL, M. O portfólio na avaliação do ensino superior. Trabalho apresentado no 12. ${ }^{\circ}$ ENDIPE, Curitiba, agosto de 2004.

SAMPAIO, M. N.; LEITE, L. S. Alfabetização tecnológica do professor. 2. ed. Petrópolis: Vozes, 2000.

SOARES, M. Novas práticas de leitura e escrita: letramento na cibercultura. Educação e Sociedade, Campinas, v. 23, n. 81, p. 143-160, dez. 2002.

VIÑAO FRAGO. Alfabetização na história e na sociedade. Rio de Janeiro: Vozes, 1993.

VYGOTSKY, L. S. Pensamento e linguagem. São Paulo: Martins Fontes, 1989.

Texto recebido em 15 nov. 2004

Texto aprovado em 12 jan. 2005 